\title{
Impact of Residual Spraying on Rhodnius prolixus and Triatoma dimidiata in the Department of Zacapa in Guatemala
}

\author{
J Nakagawa $/{ }^{+}$, C Cordón-Rosales*, J Juárez**, C Itzep**, T Nonami
}

Japan International Cooperation Agency, Oficina de Voluntarios Japoneses, 18 Calle, 5-56 Zona 10 Unicentro 12 nivel Oficina 1203, Guatemala, Guatemala *Universidad del Valle de Guatemala/Center of Disease Control-Medical Entomology Research and Training Unit/Guatemala, Guatemala **Ministerio de Salud Pública y Asistencia Social de Guatemala, Guatemala

As a vector control program to control Chagas disease in Guatemala, residual spraying of Rhodnius prolixus and Triatoma dimidiata was performed, and its impact was measured in the department of Zacapa. In order to identify infested villages and determine the degree of infestation, a baseline entomological survey to identify municipalities infested with vectors followed by an additional vector survey in areas known to be infested was conducted. Residual spraying using pyrethroid insecticides was performed at all the villages identified as being infested with the vectors. The residual spraying was shown to be highly effective against both vectors by the decrease in infestation indices after spraying. Analysis of the cost-effectiveness of the spraying showed that the average cost of insecticides per house is high when compared with that in Southern Cone countries.

Key words: Chagas disease - Rhodnius prolixus - Triatoma dimidiata - vector control - cost analysis - Guatemala

Chagas disease is one of the most serious vector-born diseases in Guatemala. It is estimated that in Guatemala 4,000,000 people are at risk for Chagas disease, 730,000 people are currently infected, and 30,000 people are infected annually (Hayes \& Schofield 1990, OPS 2000, Schofield 2000). Chagas disease is a parasitic infection that in its chronic stage produces irreversible organ damage. It is caused by a flagellate protozoan, Trypanosoma cruzi, which is transmitted to humans through the feces of blood-sucking triatomine bugs. There are three domiciliated triatomine species in Guatemala: Rhodnius prolixus, Triatoma dimidiata, and Triatoma nitida, with the main vector species being $R$. prolixus and T. dimidiata (Schofield \& Dujardin 1997).

$R$. prolixus is a much more efficient vector than $T$. dimidiata in transmitting T. cruzi (Ponce 1999). It appears to be exclusively domestic in Central America and can be eliminated (Schofield \& Dujardin 1997, Dujardin et al. 1998). On the other hand, T. dimidiata has reported silvatic ecotopes, and is widespread in peridomestic and domestic habitats (Zeledon 1981).

Through a national survey of triatomine infestation of 236 villages in 22 departments between 1995 and 1997, it was shown that the populations in the departments in the Eastern part of the country were at highest risk of Chagas disease transmition (Tabaru et al. 1999). T. dimidiata is reported to be distributed in 21 of 22 departments (OPS 2002), while $R$. prolixus is limited to five departments (Tabaru et al. 1999) with infestation indices between 0 and $34.5 \%$, and dispersion indices from 0 to $85.7 \%$ (Tabaru et al. 1999). In 1997, World Health Organization (WHO) and

${ }^{+}$Corresponding author. Fax: 81-54-643-3439. E-mail: junnakagawa@hotmail.com

Received 8 August 2002

Accepted 24 January 2003 the Central American countries set a goal for the elimination of the transmission of Chagas disease by the end of 2010 through the elimination of $R$. prolixus, reduction in the distribution of $T$. dimidiata, and elimination of the transmission of $T$. cruzi through blood transfusion. In January 2000, the Ministry of Health of Guatemala initiated a vector control program directed at eliminating Chagas disease transmission in five departments (Zacapa, Chiquimula, Jutiapa, Santa Rosa, and Jalapa) in the Eastern region of Guatemala under the decentralized health system in collaboration with Japan International Cooperation Agency (JICA), the Pan American Health Organization, the University of San Carlos of Guatemala, and the Medical Entomology Research and Training Unit/Guatemala, the Center for Disease Control of the United States and the Center for Health Studies/University of Valle of Guatemala (UVG/CDC-MERTUG). Under the health area integrated system (SIAS: Sistema Integral de la Atención en Salud) which is a decentralized health administration system, each department is administered as a "health area (area de salud)". Each health area is responsible for executing health programs such as the vector control operation in each department.

The objective of the study is to evaluate the feasibility of our vector control operation by determining the impact on the vectors of residual spraying, which is evident by change in the house infestation rate in the department of Zacapa.

\section{MATERIALS AND METHODS}

The department of Zacapa $\left(15^{\circ} 11 \mathrm{~N}\right.$ and $\left.89^{\circ} 30 \mathrm{E}\right)$ is located $152 \mathrm{~km}$ east of Guatemala City (Figure), and has a population of 200,000 including 40,318 houses and 370 villages in ten municipalities. This department is infested with $R$. prolixus and $T$. dimidiata, with an infestation index of $7.8 \%$ and a dispersion index of $28.6 \%$ (Tabaru et al. 1999). All the infested villages were targeted for the vector control operation. Our vector control operation in the department of Zacapa includes a base-line entomological 
survey, an operational vector survey targeted at high-risk areas, residual spraying of insecticides, cost-analysis of the spraying, and a post-spraying vector survey. The vector control was targeted at all the houses in each infested village in the department of Zacapa. From the entomological indicators suggested by WHO for control of Chagas disease vectors, we used the following indices: infestation index $=$ number of houses infested by triatomines/number of houses examined $\mathrm{x} 100$; dispersion index $=$ number of villages infested with triatomines/number of villages examined x 100 (WHO 1991, Schofield 2001).

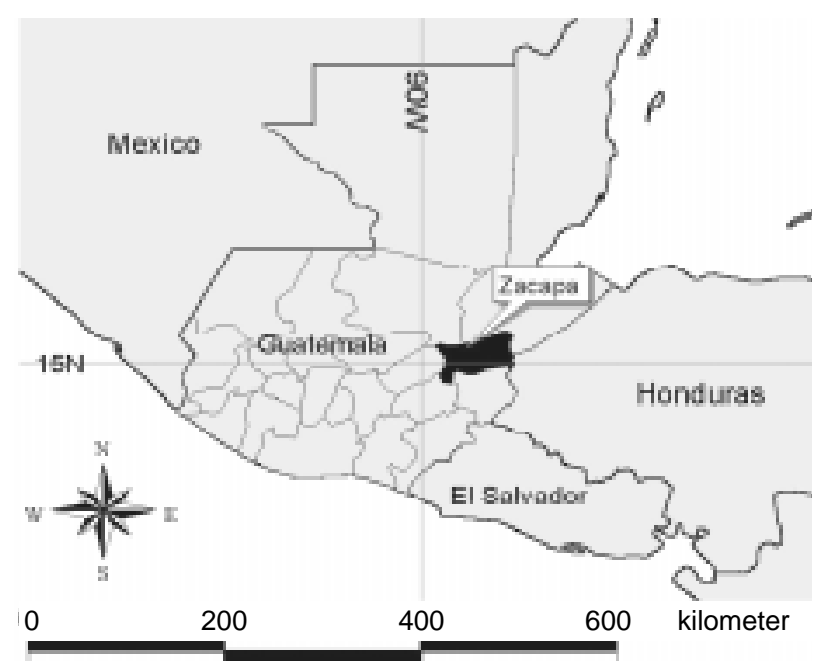

Location of the department of Zacapa, Guatemala

We focused on calculating the infestation index, since the vector control operation targeted infested houses, and we can easily follow the reduction in the number of infested houses using an operational survey. In our surveys, we calculated the infestation index at the municipality level in order to identify the infestation level, and to determine the impact of residual spraying. The baseline entomological surveys were performed in randomly selected samples of villages, statistically representative at the municipality level. Two teams of two persons from the vector-born disease section (ETV; Enfermedades Transmitidas por Vectores) of the health area of Zacapa and UVG/CDC-MERTUG performed the survey. The survey was conducted in 1,403 houses in 121 villages in ten municipalities during the period of May through August of 2000 .

In order to locate villages infested with triatomines, an operational vector survey was performed in the villages suspected of being infested with $R$. prolixus and $T$. dimidiata, where infestation was reported or in rural areas where the majority of the houses are constructed with mud walls and/or thatched roofs. Two teams of five persons from the ETV section of the health area of Zacapa with the collaboration of health volunteers performed this survey. The operational survey was conducted in 952 houses at 71 villages in ten municipalities during the periods of March through August of 2000. We conducted an additional survey at 36 villages that were investigated by the baseline survey, but none of the houses were searched twice before the application of insecticides. A total of 1,905 houses in 156 villages in all the ten municipalities were surveyed in these two surveys. Using data from these two surveys, we calculated the infestation index for all infested villages by municipalities.

In both the baseline survey and the operational survey, between 3 and 44 houses were visited per village, depending on the size of the village. Each member of the team, equipped with a search light and tweezers searched the inside of the house and peridomestic structures such as chicken coops, stables, goat corrals, etc. Each house was searched for vectors for $30 \mathrm{~min}$ by one team member, or $15 \mathrm{~min}$ by two team members. The house was counted as infested if at least one vector was found.

Residual spraying of pyrethroid insecticides on internal walls and roofs of the houses, and peridomestic structures, was performed at all the houses in the villages found by both surveys to be infested with $R$. prolixus and/or $T$. dimidiata. We used two types of pyrethroid insecticides; deltamethrin (5\% wettable powder at $25 \mathrm{mg}$ a.i./m) and beta-cyfluthrin $(12.5 \%$ suspension concentrate at $25 \mathrm{mg}$ a.i./m), both of which were used for Chagas vector control in South and Central America and produced successful results (Zerba 1999, Schofield 2000), as well as having the lowest price at the time of purchase. JICA purchased deltamethrin in April 2000, and the Ministry of Health purchased beta-cyfluthrin in October 2000. Deltamethrin was used first until the entire quantity was sprayed, and then beta-cyfluthrin was used to complete the spraying operation. Approximately $100 \mathrm{~g}$ of deltamethrin or $40 \mathrm{ml}$ of beta-cyfluthrin, equivalent to one spraypack per house, was allocated for spraying at a rate of $40 \mathrm{ml} / \mathrm{m}^{2}$, using 81 Guarany or 81 Hudson X-pert spraypacks. Deltamethrin was used in the municipalities of Huite, Cabañas, Usumatlàn, and Estanzuela. Beta-cyfluthrin was used in Gualan, San Diego and Rìo Hondo. In the municipalities of La Uniòn, Zacapa, Teculutàn, both insecticides were used. The spraying was performed between August and November 2000. Each of the twelve trained personnel sprayed an average of eight houses per day for four months under the supervision of the ETV section of the health area of Zacapa.

ETV personnel visited each household the day before the spraying to explain the procedure and to request removal of all the furniture in the house. On the day of the spraying, each technician explained to the residents basic information about Chagas disease, such as its cause, the type of vectors, ways to prevent infestation, and the reporting procedure in case of reinfestation (if a vector is found in the house, the residents should put it in a plastic bag and take it to the nearest health service post to have it analyzed for the presence of $T$. cruzi). A brochure that explains the above information was handed out to each household, as well.

A post-spraying vector survey was performed in all the infested villages six to nine months after spraying. The surveys were conducted from May to July 2001. Two ETV teams consisting of ten people from the health area of Zacapa conducted the survey, using the same method- 
ology as that for the operational surveys. Previously infested houses were selected for the survey.

We calculated the average cost of spraying, insecticides, and transportation per house. We added the cost of the insecticides, the salaries of the contracted personnel, and the cost of transportation (fuel and maintenance of a vehicle) for the operation. We divided the total cost by the number of sprayed houses.

\section{RESULTS}

The baseline survey identified the characteristics of the infestation by $R$. prolixus and $T$. dimidiata in the department of Zacapa. Table I shows the infestation index of both vectors. The infestation index was $3.4 \%$ overall, $1.8 \%$ for $R$. prolixus and $1.9 \%$ for $T$. dimidiata. Among the ten municipalities, the infestation index was highest in Zacapa (9.9\%), followed by Río Hondo (5.3\%). The dispersion index was $18.3 \%, 14 \%$ for T. dimidiata, and $5 \%$ for $R$. prolixus.

As a result of the operational survey, an additional 40 villages were identified as being infested with $T$. dimidiata and $R$. prolixus. $R$. prolixus was only found in intradomestic areas, while T. dimidiata was found both in intra- and peri-domestic areas. Among a total of 62 infested villages, $R$. prolixus was found in 32 villages, and $T$. dimidiata was found in 37 villages. Six villages were found to be infested with both species. The infestation index for the 62 infested villages was $14 \%$ in total, $8.8 \%$ for $R$. prolixus and $5.3 \%$ for T. dimidiata. The infestation rate for $R$. prolixus was particularly high in the municipalities of La Union (15.2\%), Usumatlán (14.4\%), and Zacapa (14.4\%). The infestation rate for T. dimidiata was highest in the municipalities of Rio Hondo (21.3\%), followed by Huite $(8.5 \%)$.

Residual spraying was performed at a total of 5,286 houses out of the 5,684 houses (93\%) located in the 62 triatomine-infested villages. The majority of the residents welcomed the spraying; 398 houses (7\%) were not sprayed due to the absence of the residents (329 houses), or the refusal to allow spraying by the residents ( 69 houses). A total of $356.4 \mathrm{~kg}$ of deltamethrin and 55.91 of beta-cyfluthrin was sprayed, and an average of $89 \mathrm{~g}$ of deltamethrin and $35.6 \mathrm{ml}$ of beta-cyfluthrin was used per house. The spraying was performed between August and November 2000.

As a result of the spraying intervention, the infestation index dropped significantly for $R$. prolixus and $T$. dimidiata. Table II compares the infestation index of infested villages pre- and post-spray intervention. After the spraying, the infestation index decreased from $14 \%$ to $0.8 \%$ in total, from $8.8 \%$ to $0 \%$ for $R$. prolixus, and from $5.3 \%$ to $0.5 \%$ for $T$. dimidiata. The infestation index dropped drastically in the municipalities infested with $R$. prolixus. The infestation index of $R$. prolixus decreased in highly infested municipalities such as La Union (from $15.2 \%$ to $1 \%$ ), Zacapa (from $14.4 \%$ to $0 \%$ ), and Usumatlan (from $14.4 \%$ to $0 \%$ ).

In the case of T. dimidiata, the infestation index decreased from $21.3 \%$ to $4.4 \%$ in the municipality of Rio Hondo. In Cabañas, the infestation of T. dimidiata remained unchanged after the intervention. Before spraying, five villages were infested, two (Poblaciòn Cabañas, San Luis) with $T$. dimidiata (one infested house per village), and three with $R$. prolixus (Los Achiotes and Los Encuentros with two infested houses each, and Santo Tomas with one). After the spraying, while no R. prolixus was found, T. dimidiata were found in two villages previously not infested by $T$. dimidiata (Los Achiotes and Santo Tomas with one infested house each). The reasons for the unchanged infestation index could be infestation from outside foci, or survival from domiciliary foci which might have been overlooked during the survey before the insecticide spraying.

Both deltamethrin and beta-cyfluthrin proved to be effective against both $R$. prolixus and $T$. dimidiata as shown in Table III. Compared to the cost for salaries and transportation, the major cost of house spraying was the cost of the insecticide. The average cost of spraying each house was US\$9.12 (Table IV). The average cost of insecticide/house is US\$6.57. The cost of 12 contracted personnel was US $\$ 2.23 /$ house. The cost of transport was US\$0.32/house.

TABLE I

The results of the baseline randomly sampled entomological survey of Rhodnius prolixus and Triatoma dimidiata in the department of Zacapa

\begin{tabular}{lcccc}
\hline & & \multicolumn{3}{c}{ Infestation index $(\%)$} \\
\cline { 2 - 5 } Municipalities & Inspected houses & Combined & R. prolixus & T. dimidiata \\
\hline Cabañas & 126 & 0.7 & 0 & 0.7 \\
Estanzuela & 46 & 0 & 0 & 0 \\
Gualán & 157 & 0.6 & 0 & 0.6 \\
Huíte & 151 & 4.6 & 3.8 & 0.6 \\
La Unión & 159 & 4.4 & 0 & 5.3 \\
Río Hondo & 151 & 5.3 & 0 & 1.5 \\
San Diego & 135 & 1.5 & 0 & 0 \\
Teculután & 155 & 0 & 4.1 & 0 \\
Usumatlán & 172 & 4.1 & 6 & 4 \\
Zacapa & 151 & 9.9 & 1.8 & 1.9 \\
\hline Total & 1,403 & 3.4 & & \\
\hline
\end{tabular}

A total of 121 villages were investigated. 
TABLE II

Comparison of infestation index (\%) of Rhodnius prolixus and Triatoma dimidiata before and after residual spraying of infested villages in the department of Zacapa in Guatemala

\begin{tabular}{|c|c|c|c|c|c|c|c|c|}
\hline \multirow[b]{2}{*}{ Municipalities } & \multicolumn{4}{|c|}{ Pre-spraying } & \multicolumn{3}{|c|}{ Post-spraying } & \multirow[b]{2}{*}{ T. dimidiata } \\
\hline & $\begin{array}{c}\text { Inspected } \\
\text { houses }\end{array}$ & Combined & R. prolixus & T. dimidiata & $\begin{array}{c}\text { Inspected } \\
\text { houses }\end{array}$ & Combined & R. prolixus & \\
\hline Cabañas & 65 & 10.8 & 7.7 & 3.1 & 65 & 3.1 & 0 & 3.1 \\
\hline Estanzuela & 21 & 4.8 & 0 & 4.8 & 21 & 0 & 0 & 0 \\
\hline Gualán & 35 & 8.6 & 5.7 & 2.9 & 35 & 0 & 0 & 0 \\
\hline Huité & 188 & 12.8 & 4.3 & 8.5 & 170 & 0 & 0 & 0 \\
\hline La Unión & 191 & 16.8 & 15.2 & 2.1 & 197 & 1.5 & 1 & 0.5 \\
\hline Río Hondo & 47 & 21.3 & 0 & 21.3 & 46 & 4.4 & 0 & 4.4 \\
\hline San Diego & 70 & 7.1 & 0 & 7.1 & 46 & 0 & 0 & 0 \\
\hline Teculután & 80 & 6.3 & 0 & 4.4 & 78 & 0 & 0 & 0 \\
\hline Usumaltán & 97 & 16.5 & 14.4 & 2.1 & 97 & 0 & 0 & 0 \\
\hline Zacapa & 153 & 19 & 14.4 & 4.6 & 168 & 0 & 0 & 0 \\
\hline Total & 947 & 14 & 8.8 & 5.3 & 923 & 0.8 & 0 & 0.5 \\
\hline
\end{tabular}

A total of 62 villages were investigated before and after the spraying.

TABLE III

Comparison of infestation index $(\%)$ of Rhodnius prolixus and Triatoma dimidiata by sprayed insecticide before and after residual spraying of infested villages in the department of Zacapa in Guatemala

\begin{tabular}{|c|c|c|c|c|c|c|c|c|}
\hline \multirow[b]{3}{*}{ Insecticides } & \multicolumn{4}{|c|}{ Pre-spraying } & \multicolumn{4}{|c|}{ Post-spraying } \\
\hline & \multirow{2}{*}{$\begin{array}{c}\text { Inspected } \\
\text { houses }\end{array}$} & \multicolumn{3}{|c|}{ Infestation index } & \multirow{2}{*}{$\begin{array}{c}\text { Inspected } \\
\text { houses }\end{array}$} & \multicolumn{3}{|c|}{ Infestation index } \\
\hline & & Combined & R.prolixus & T. dimidiata & & Combined & R. prolixus & T. dimidiata \\
\hline Deltamethrin & 710 & 14 & 9.9 & 4.4 & 681 & 0.6 & 0.1 & 0.4 \\
\hline Beta-cyfluthrin & 237 & 13.5 & 5.1 & 8.9 & 242 & 1.2 & 0.4 & 0.8 \\
\hline
\end{tabular}

Among the 62 infested villages, deltamethrin was sprayed in 4,059 houses, and beta-cyfluthrin was sprayed in 1,625 houses.

TABLE IV

Cost of the spraying operation of 5,286 houses in Zacapa $(\mathrm{US} \$)^{a}$

\begin{tabular}{lcc}
\hline & Cost & Cost per house \\
\hline Insecticide $^{b}$ & $34.752,00$ & 6,57 \\
Labor $^{c}$ & $11.788,80$ & 2,23 \\
Transport $^{d}$ & $1.684,90$ & 0,32 \\
\hline Total & $48.225,70$ & 9,12 \\
\hline
\end{tabular}

$a$ : US\$1 was approximately 7.8 Quetzales (Q) at time of spraying; $b$ : the cost of deltamethrin is US $\$ 72 / \mathrm{kg}$, and that of beta-cyfluthrin is US $\$ 160 / 1 ; c$ : the cost of labor includes the monthly salaries (US\$245,60) of 12 contracted personnel for spraying for four months; $d$ : the cost of transport includes fuel and the cost of the maintenance of the vehicle; 505.96 gallons of diesel oil (US\$1,36/ gallon) was used, and US $\$ 996,79$ was spent on the maintenance of the vehicle.

\section{DISCUSSION}

The results of the pre- and post-spraying surveys showed that one-time spraying worked well against both vectors. Since the $R$. prolixus is a domestic vector, insecticide spraying alone could eliminate the vector. The elimination of $R$. prolixus is attainable by spraying $100 \%$ of the houses in the infested villages, and by a second round of spraying (which has been initiated in September 2001). However, in order to assure the elimination of $R$. prolixus in Zacapa, $100 \%$ of the houses in the infested villages need to be sprayed. Also it is necessary to conduct evaluations using not only manual searches of the houses, but also utilizing passive monitoring tools such as traps, and white paper pinned to a wall to monitor the deposition of feces of triatomine vectors (Schofield 2001).

In the case of $T$. dimidiata, the spraying worked well, and the infestation rate declined significantly 6-9 months after spraying. However, reinfestation by $T$. dimidiata has been observed after the residual spraying of pyrethroids in Central America (Oliveira Filho 1997). In order to avoid reinfestation after spraying, and to make our intervention strategy sustainable, continued vigilance of vector infestation in both sprayed and non-sprayed villages by the residents and by health personnel of the health area is necessary. To do so, health volunteers, schoolteachers, community leaders should be involved and trained. In addition, we have started operations to check the infestation and colonization index separately for intra- and peri-domestic infestation in order to evaluate the control of intra-domestic infestation and colonization which is critical for human transmission of T. cruzi (WHO 2002).

It was found that the cost of insecticides is high in Guatemala. The average cost of spraying insecticides per 
house in the Southern Cone region (Argentine, Brazil, Uruguay, Paraguay, Chile, and Bolivia) is US\$4.00 (OPS 1998). In Brazil, the major cost of spraying for Chagas disease vectors is salary and transportation costs, and not insecticides (Olveira Filho 1989, Schofield \& Dias 1991, Akhavan 2000). Negotiation should be undertaken to lower the costs in order to increase the coverage of vector control with limited financial resources.

\section{ACKNOWLEDGEMENTS}

To the ETV section of the health area of Zacapa and the survey team of UVG/CDC-MERTUG for their contribution to the operational survey. To Drs Chris Schofield, Yoichi Yamagata, Robert Klein, and Yuichiro Tabaru for their advice.

\section{REFERENCES}

Akhavan D 2000. Análise de Custo-efetividade do Programa de Controle da Doença de Chagas no Brasil, OPAS/OMS Representação do Brasil, Brasília, p. 44-48.

Dujardin JP, Muñoz M, Chavez T, Ponce C, Moreno J, Schofield CJ 1998. The origin of Rhodnius prolixus in Central America. Med Vet Entomol 12: 113-115.

Hayes RJ, Schofield CJ 1990. Estimacion de las tasas de incidencia de infecciones y parasitosis cronicas a partir de la prevalencia: la enfermedad de Chagas en America Latina. Bol OPS 108: 308-316.

Oliveira Filho AM 1989. Cost-effectiveness analysis in Chagas disease vector's control interventions. Mem Inst Oswaldo Cruz 84 (Suppl. IV): 409-417.

Oliveira Filho AM 1997. Uso de nuevas herramientas para el control de triatomines en diferentes situaciones entomologicas en el continente americano. Rev Soc Bras Med Trop 30: 41-46.

OPS-Organización Panamericana de Salud 1998. VII Reunión de la Comisión Intergubernamental para la eliminación de Triatoma infestans y la interrupción de la transmisión de la tripanosomiasis americana por transfusión, Document OPS/ HCP/HCT/98.114, Organización Panamericana de Salud, Washington DC, 78 pp.

OPS-Organización Panamericana de Salud 2000. Segunda Reunión de la Comisión Intergubernamental de la iniciativa de Centroamérica y Belice para la interrupciòn de la transmisión vectorial de la enfermedad de Chagas por Rhodnius prolixus, disminución de la infestaciòn domiciliaria por Triatoma dimidiata, y eliminación transmisión transfusional del Trypanosoma cruzi. Document OPS/HCP/HCT/ 164/00, Organización Panamericana de Salud, Washington DC, $21 \mathrm{pp}$.

OPS-Organización Panamericana de Salud 2002. Taller para el Establecimiento de Pautas Técnicas en el Control de Triatoma dimidiata, Document OPS/HCP/HCT/214/02, Organización Panamericana de Salud, Washington DC, 8 pp.

Ponce C 1999. Hacia la eliminación de la transmisión del Trypanosoma cruzi en Honduras y los paises de America Central. Medicina 59 (Supl. II): 118-119.

Schofield CJ 2000. Challenges of Chagas Disease Vector Control in Central America, Global Collaboration for Development of Pesticides for Public Health, WHO/CDS/WHOPES/ GCDPP/2000.1, p. 4-5.

Schofield CJ 2001. Field Testing and Evaluation of Insecticides for Indoor Residual Spraying against Domestic Vectors of Chagas Disease, Global Collaboration for Development of Pesticides for Public Health. WHO/CDS/WHOPES/ GCDPP/2001.1, 14-15, p. 27-28.

Schofield CJ, Dias JCP 1991. A cost benefit analysis of Chagas disease control. Mem Inst Oswaldo Cruz 86: 285-295.

Schofield CJ, Dujardin JP 1997. Chagas disease vector control in Central America. Parasitol Today 13: 141-144.

Tabaru Y, Monroy C, Rodas A, Mejia M, Rosales R 1999. The geographical distribution of vectors of Chagas disease and population at risk of infestation in Guatemala. Med Entomol Zool 50: 3-8.

WHO-World Health Organization 1991. Control of Chagas Disease, WHO Technical Report Series 811, p. 51-52.

WHO-World Health Organization 2002. Control of Chagas Disease, WHO Technical Report Series 905, p. 73, 82-83.

Zeledón R 1981. El Triatoma dimidiata (Latreille, 1811) y su Relación con la Enfermedad de Chagas, Editorial Universidad Estatal a Distancia, San José, Costa Rica, 146 $\mathrm{pp}$.

Zerba EN 1999. Past and Present of Chagas Vector Control and Future Needs. Global Collaboration for Development of Pesticides for Public Health, WHO/CDS/WHOPES/ GCDPP/1999.1, p. 8-10. 
282 Triatomine Control in Zacapa, Guatemala • J Nakagawa et al. 